\title{
The impact of coping on the somatic and mental status of patients with COPD: a cross-sectional study
}

Ion Papava'

Cristian Oancea ${ }^{2}$

Virgil Radu Enatescu'

Ana Cristina Bredicean'

Liana Dehelean'

Radu Stefan Romosan'

Bogdan Timar ${ }^{3}$

'Department of Neurosciences Discipline of Psychiatry, ${ }^{2}$ Department of Infectious Diseases, ${ }^{3}$ Department of Functional Sciences, "Victor Babes" University of Medicine and Pharmacy,

Timișoara, Romania
Correspondence: Cristian Oancea Department of Infectious Diseases, "Victor Babes" University of Medicine and Pharmacy, 2 EftimieMurgu, 3004I

Timișoara, Romania

Tel +40 769221057

Email oancea@umft.ro
This article was published in the following Dove Press journal:

International Journal of COPD

20 June 2016

Number of times this article has been viewed

Background and objectives: Chronic obstructive pulmonary disease (COPD) is one of the most debilitating somatic diseases, having anxiety and depression frequently as comorbidities. The coping style, the way in which the subject manages to control the difficult and stressful situations of life, can influence its evolution and also the existence of the comorbidities. In this study, coping styles in a group of subjects with COPD and their association with the intensity of depressive and anxiety symptoms as well as medical determinants were identified.

Materials and methods: In this cross-sectional study, 28 male patients with COPD risk class D were enrolled. The patients performed spirometry tests, Borg scale, 6-minute walking test, Hospital Anxiety and Depression Scale, and COPE Inventory were recorded.

Results: According to their higher coping subscale score, the depression score was the highest in patients with avoidance-type coping and the lowest in patients with problem-focused coping (11.0 vs 5.6; $P=0.042$ ), respectively, patients with social support-focused coping having the highest anxiety score in contrast to patients with emotion-focused coping, which had the lowest anxiety score ( 11.6 vs $5.0 ; P=0.006$ ). Regarding respiratory parameters, significant differences were present for the variation of the medians between the four groups only for forced vital capacity (FVC\%) (the lowest $\mathrm{FVC} \%$ was in patients with predominant social support-focused coping and the highest in patients with problem-focused coping) and 6-minute walking test (\%) (the lowest score for patients with social support-focused coping and the highest value in patients with avoidance-type coping). Problem-coping score was significantly and positively associated with $\mathrm{FVC} \%$ (Spearman's $r=0.400 ; P=0.035$ ), emotion-focused coping score was significantly and positively associated with FVC \% (Spearman's $r=0.395 ; P=0.038$ ), and social support-focused coping score was negatively and significantly correlated with forced expiratory volume in 1 second/FVC\% ratio (Spearman's $r=0.389 ; P=0.041$ ). A significant, negative correlation was found only between depression score and forced expiratory volume in 1 second (Spearman's $r=-0.435 ; P=0.026$ ) with respect to psychiatric symptoms.

Conclusion: Coping styles in patients with COPD affect the intensity of associated depressive and anxiety symptoms as well as medical determinants, thus the coping style should be considered an important part in the multidisciplinary approach of these patients.

Keywords: COPD, COPE, Hospital Anxiety and Depression Scale, depression, anxiety

\section{Introduction}

Chronic obstructive pulmonary disease (COPD) is one of the most prevalent and debilitating disease in adults all over the world. It is a progressive airway disease associated with psychological distress. ${ }^{1}$ Therefore, two of the most frequent comorbidities of COPD are depression and anxiety; some studies mention the presence of depressive and anxious symptoms in over $70 \%$ of cases. ${ }^{2-8}$ Failure in identifying and

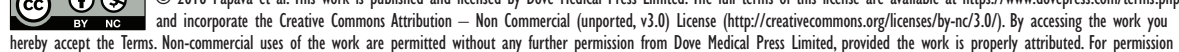
for commercial use of this work, please see paragraphs 4.2 and 5 of our Terms (https://www.dovepress.com/terms.php).
s. 
treating the depressive and anxious symptoms in patients with COPD has a negative impact on the quality of life and medical outcomes, contributing to a substantial burden of COPD-related morbidity. ${ }^{9,10}$

A recent meta-analysis of 25 studies on subjects with COPD, that was designed to find a connection between depression and this disease, considers this relation to be bidirectional: depression can be both a cause and a consequence of COPD. ${ }^{11}$ The mechanism that determines the frequent association of COPD with depression and anxiety has not been identified yet; therefore, further studies in this direction are necessary. The existence of at least three comorbidities in patients with COPD (eg, myocardial infarction, lung cancer, depression, anxiety, and hip fracture) results in an increased frequency of their hospitalization, and also in their premature mortality. ${ }^{12,13}$

A greater amount of information sustains the impact of psychological stress on the somatic level, such as pulmonary function, exercise capacity, and pulmonary-specific symptoms of COPD. ${ }^{14-17}$

Therefore, the way in which a subject manages this stress (the style of coping used) might become an important factor in the progression of the illness, as well as in its successful treatment and rehabilitation. Teaching adequate coping strategies should be considered for a better control of the disease.

Coping represents a psychological process developed at a conscious level that we use when we try to manage the difficult and stressful situations of life. The coping style can be both adaptive, implying the stress reduction, and maladaptive, situation in which the maintenance and the amplification of the current symptomatology are present or can determine the appearance of some new symptomatic elements and behaviors. It can also influence the person's reaction at a biological level leading to a normal or pathological reaction of the human subject, depending on its efficiency in reducing the psychological distress. ${ }^{18}$

Therefore, it is important to identify the impact of coping style both on the maintenance or in the reduction of anxiety or depression symptoms and also on respiratory parameters and exercise tolerance in COPD. After identifying the type of association between the coping styles used by COPD patients and the aforementioned aspects, we can hope to improve the psychotherapeutic intervention as well as the recovery and prevention of exacerbation in terms of time and costs.

The aim of this study was to identify the coping styles of a group of people suffering from COPD and the association of this group with the depressive and anxious symptomatology and with the medical determinants.

\section{Materials and methods}

This study included 28 male patients with COPD risk class D (patients who present more than two exacerbation per year, having a modified Medical Research Council score $>2$, and a COPD Assessment Test score $>10$, being spirometric classified in class Global Initiative for Chronic Obstructive Lung Disease [GOLD] 3-4; $\mathrm{FEV}_{1}<50 \%$ predicted) who came to a control visit and who met the GOLD criteria (Table 1). ${ }^{19}$ Prior to participation in the study, all patients signed an informed consent form. The consent forms and the study were approved by the Psychiatric Clinic "Eduard Pamfil".

Inclusion criteria: male patients $>60$ years, former smoker $>10$ packs/year, COPD GOLD class D without exacerbation of respiratory symptoms in the last 2 months, and no mental illness or use of drugs that could influence the tests.

Exclusion criteria: dementia, psychosis, acute suicide or homicide risk, other somatic illnesses (eg, cancer) that could possibly cause death in the near future. On admission day, all the data were collected, and the self-administered psychiatric questionnaires were filled in by the patients. On the same day, spirometry tests were performed in the patients using Jaeger device (Wuerzburg, Germany).

The measurement of maximal inspiratory pressure (MIP) and maximal expiratory pressure (MEP) was performed with the same device. This test is a quick and noninvasive clinical procedure for determining the index o inspiratory and expiratory muscle strength. It is useful in assessing the degree of abnormality and in monitoring respiratory muscle weakness in individual patients over time. ${ }^{20}$

On admission day, the participants filled in the following two psychiatric questionnaires:

1. COPE Inventory: Elaborated by Carver et al, ${ }^{21}$ COPE questionnaire is an instrument of self-defense that assesses the strategies that people use to cope with difficult or stressful life events. The scale contains 60 questions with answers rated on a scale from 1 to 4 : where 1 represents "I usually don't do this thing" and 4 represents "I often do this thing". The evaluation of the modalities of coping was done by analyzing the next four levels: 1) problem-focused

Table I Patients' demographic data

\begin{tabular}{|c|c|}
\hline Age (years) ${ }^{a}$ & $59.9 \pm 6.0$ \\
\hline Body mass index $\left(\mathrm{kg} / \mathrm{m}^{2}\right)^{\mathrm{a}}$ & $24.5 \pm 5.9$ \\
\hline Education (years) ${ }^{\mathrm{b}}$ & $12(0)$ \\
\hline Depression (score) ${ }^{\mathrm{a}}$ & $7.3 \pm 3.9$ \\
\hline Anxiety (score) ${ }^{\mathrm{a}}$ & $7.9 \pm 4.2$ \\
\hline Smokers (\%) & 100 \\
\hline
\end{tabular}

Notes: ${ }^{2}$ Variables from Gaussian distributed populations. Results are presented as mean \pm standard deviation. 'Variables from nonparametric distributed populations. Results are presented as median (interquartile range). 
coping, which includes planning, active approach, and deletion of concurrent activities; 2) emotion-focused coping, which includes the positive interpretation and growth, restraint, and acceptance; 3) social support-focused coping, which includes the use of the social-instrumental support, the use of the social-emotional support, and the expression of feelings (venting of emotions); and 4) avoidant coping, which includes denial, mental, and behavioral deactivation. Higher subscale scores indicate greater use of that coping strategy. ${ }^{22}$

2. The Hospital Anxiety and Depression Scale is a selfadministered questionnaire that detects and distinguishes between anxiety and depression and measures the severity of emotional disorder. The questionnaire consists of just 14 items selected to be relatively unaffected by physical illness; hence, it is quick to complete. It contains two subscales: one evaluates anxiety and the other evaluates depression (each of them consists of seven items). Each item has four possibilities/alternatives of answers that reflect the severity marked from 0 to 3 . The two subscale scores are registered separately from 0 to 21 . The appreciation score of the intensity of anxiety and depression is the following: 0-7 normal, 8-10 mild, 11-14 moderate, and 15-21 severe.

Functional exercise capacity was assessed using the 6-minute walking test (6MWT) according to the guidelines of the American Thoracic Society. ${ }^{23}$ The shortness of breath was evaluated with the Borg scale in which the subjects report symptoms associated with a current physical activity. The Borg scale rates dyspnea on a scale of $0-10$ to quantify the intensity of shortness of breath during activity.

The coping style was compared using the following medical determinants: forced vital capacity (FVC), forced expiratory volume in 1 second $\left(\mathrm{FEV}_{1}\right)$ obtained though spirometry, MIP, MEP, functional exercise level through 6MWT, and dyspnea with the help of the Borg scale.

According to their higher coping subscale scores, they were classified into one dominant coping type as follows: patients with problem-focused coping type, emotion-focused coping, social support-focused coping, avoiding coping type. Based on this classification, the studied group was divided into four subcohorts and was analyzed accordingly.

\section{Statistical analysis}

Data were collected and analyzed using the SPSS v.17 software suite (SPSS Inc., Chicago, IL, USA) and are presented as medians and interquartile range for continuous variables without Gaussian distribution or average \pm standard deviation for continuous variables with Gaussian distribution.
To assess the significance of the differences between groups (problem-focused coping, emotion-focused coping, social support-focused coping, and avoidance-type coping), MannWhitney $U$ and Kruskal-Wallis tests (medians, non-Gaussian populations), unpaired $t$-student, and analysis of variance (averages, Gaussian populations) tests, respectively, were used. Continuous variable distributions were tested for normality using Shapiro-Wilk test. The correlation between studied variables was evaluated using Spearman's rank sum correlation coefficient (non-Gaussian distributed variables), and the statistical significance was assessed using the $t$-distribution score test. In this study, a $P$-value $<0.05$ was considered as the threshold for statistical significance.

\section{Results}

In this cross-sectional study, 28 patients with COPD were enrolled. According to their higher coping subscale score, they were classified in one dominant coping type as follows: patients with problem-focused coping type $(n=9)$, emotionfocused coping $(n=10)$, social support-focused coping $(n=6)$, avoiding coping type $(n=3)$.

The four cohorts had similar general characteristics: age (average ranging from 56.3 to 61.5 years; $P=0.442$ ), body mass index (average ranging from 21.6 to $27.5 \mathrm{~kg} / \mathrm{m}^{2} ; P=0.655$ ), and education level (all medians 12 years of education; $P=0.845$ ), a fact which emphasizes that potential biases caused by these external factors are not to be found in our study.

The average coping scores in the entire studied cohort were as follows: problem-focused coping (33.2 \pm 8.2 ), emotion-focused coping (34.3 \pm 6.4$)$, social support-focused

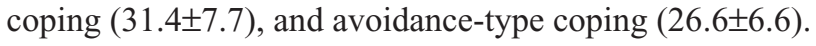

The significant differences between the four studied subgroups regarding depression and anxiety are as follows: the depression score was the highest in patients with avoidancetype coping and the lowest in patients with problem-focused coping ( 11.0 vs $5.6 ; P=0.042$ ); patients with social supportfocused coping style had the highest anxiety score in contrast to patients with emotion-focused coping who had the lowest anxiety score ( 11.6 vs $5.0 ; P=0.006$ ). Table 2 presents the detailed comparison of the studied characteristics between the four subgroups.

With regard to respiratory parameters, significant differences were present for the variation of the medians among the four groups only for $\mathrm{FVC} \%$ and 6MWT (\%); patients with social support-focused coping type had the lowest FVC\% $(43 \%)$, and this value increases for patients with emotionfocused coping (47.5\%), avoidance-type coping (53\%), and problem-focused coping (59\%). Regarding the 6MWT (\%), the lowest score of the scale was observed for patients with 
Table 2 Studied group characteristics stratified according to their dominant coping type

\begin{tabular}{|c|c|c|c|c|c|}
\hline Parameters & $\begin{array}{l}\text { Problem-focused } \\
\text { coping }(n=9)\end{array}$ & $\begin{array}{l}\text { Emotion-focused } \\
\text { coping }(n=10)\end{array}$ & $\begin{array}{l}\text { Social support-focused } \\
\text { coping }(n=6)\end{array}$ & $\begin{array}{l}\text { Avoidance-type } \\
\text { coping }(n=3)\end{array}$ & $P$-value \\
\hline Age (years) ${ }^{\mathrm{a}}$ & $60.4 \pm 6.3$ & $61.5 \pm 4.1$ & $58.8 \pm 10.1$ & $56.3 \pm 4.2$ & 0.442 \\
\hline Body mass index $\left(\mathrm{kg} / \mathrm{m}^{2}\right)^{\mathrm{a}}$ & $27.5 \pm 4.3$ & $24.5 \pm 8.1$ & $23.4 \pm 4.9$ & $21.6 \pm 2.6$ & 0.655 \\
\hline Education (years) ${ }^{b}$ & $12(0)$ & $12(0)$ & $12(1)$ & $12(0)$ & 0.845 \\
\hline Depression (score) ${ }^{\mathrm{a}}$ & $5.6 \pm 2.3$ & $5.9 \pm 3.6$ & $9.8 \pm 5.2$ & $11.0 \pm 1.7$ & $0.042 *$ \\
\hline Anxiety (score) $)^{\mathrm{a}}$ & $7.4 \pm 2.4$ & $5.0 \pm 3.7$ & $11.6 \pm 4.7$ & $11.3 \pm 0.6$ & $0.006^{*}$ \\
\hline Smokers (\%) & $9(100 \%)$ & $10(100 \%)$ & $6(100 \%)$ & $5(100 \%)$ & I \\
\hline
\end{tabular}

Notes: *Variations between groups are statistically significant. ${ }^{2}$ Variables from Gaussian distributed populations. Results are presented as mean \pm standard deviation. bVariables from nonparametric distributed populations. Results are presented as median (interquartile range).

social support-focused coping (26.5\%), followed by patients with emotion-focused coping (83.5\%) and problem-focused coping type (87\%), whereas the highest value was observed in patients with avoidance-type coping (99.7\%).

Although the variance among all the four groups was not statistically significant, the following patterns were observed: the $\mathrm{FEV}_{1} \%$ value was significantly lower in patients with social support-focused coping (16.5\%) compared with any of the other three groups; the MIP\% value was significantly higher in social support-focused coping type when compared with any other group; and the BORG scale score was significantly lower in patients with problem-focused coping type (a median score of 7). Table 3 presents the association between the dominant coping type and respiratory parameters.

When the association between the four coping scales and the respiratory parameters were analyzed, different patterns of relationships were observed. Problem-focused coping score was significantly and positively associated with $\mathrm{FVC} \%$ (Spearman's $r=0.400 ; P=0.035$; Figure 1). Emotion-focused coping score was positively and significantly associated with FVC\% (Spearman's $r=0.395 ; P=0.038$; Figure 2). Social support-focused coping score was negatively and significantly correlated with $\mathrm{FEV}_{1} / \mathrm{FVC} \%$ ratio (Spearman's $r=0.389 ; P=0.041$ ), which means that a more significant social support-focused coping type is associated with the lower values of this ratio (Figure 3). The other studied pairs of correlations had no statistical significance (Table 4). Regarding the association between anxiety or depression and respiratory parameters, a significant, negative correlation only between depression score and FEV (Spearman's $^{2}$ $r=-0.435 ; P=0.026$; Figure 4), denoting that patients with more advanced depression symptomatology have a decreased $\mathrm{FEV}_{1} \%$ value, was found in this study. The other pairs of studied variables were not significantly correlated (Table 5).

\section{Discussion}

The psychological features of a subject can influence his or her somatic condition, and in the case of those who suffer from COPD, it is a known fact that these can influence the way in which these people manage to control the disease toward a more favorable evolution. ${ }^{24}$

However paradoxical as it may seem, there were studies on chronic somatic diseases that have proven that psychological factors may predict an outcome announced by different physical parameters better than the clinical variables. Therefore, a more complex psychological analysis of these people is considered to be very important for the management of this disease, among the psychological factors that require review are those related to coping.

This is the first article that evaluates coping styles in patients with COPD in Romania. There are studies in literature that have successfully applied the concept of coping in COPD.

Table 3 Respiratory parameters in relation to the dominant coping type

\begin{tabular}{|c|c|c|c|c|c|}
\hline Parameters & $\begin{array}{l}\text { Problem-focused } \\
\text { coping }(n=9)\end{array}$ & $\begin{array}{l}\text { Emotion-focused } \\
\text { coping }(n=10)\end{array}$ & $\begin{array}{l}\text { Social support-focused } \\
\text { coping }(n=6)\end{array}$ & $\begin{array}{l}\text { Avoidance-type } \\
\text { coping }(n=3)\end{array}$ & $P$-value \\
\hline FVC (\%) & $59(23)$ & $47.5(12)$ & $43(16)$ & $53(4)$ & $0.044 *$ \\
\hline $\mathrm{FEV}_{1}(\%)$ & $27(8)$ & $27.5(10)$ & $16.5(15)$ & $22(3)$ & 0.249 \\
\hline $\mathrm{FEV}_{\mathrm{I}} / \mathrm{FVC}(\%)$ & $44(17)$ & 45.5 (I8) & $43.5(25)$ & $42(6)$ & 0.759 \\
\hline MIP (\%) & $56.5(34.6)$ & $52.4(31.9)$ & $64.1(21.6)$ & $56.6(4)$ & 0.527 \\
\hline MEP (\%) & $60.7(15.1)$ & $49.9(25.5)$ & $56.0(34.7)$ & $52.0(4)$ & 0.702 \\
\hline 6MWT (\%) & $87(36)$ & $83.5(48)$ & $26.5(64)$ & $99.7(0)$ & $0.024 *$ \\
\hline Borg scale score & $7(5)$ & $10(5)$ & $10(1)$ & $9(0)$ & 0.135 \\
\hline
\end{tabular}

Notes: *Variations between groups are statistically significant. Variables from non-Gaussian distributions. Results are presented as median (interquartile range).

Abbreviations: FVC, forced vital capacity; $\mathrm{FEV}_{1}$, forced expiratory volume in I second; 6MWT, 6-minute walking test; MEP, maximal expiratory pressure; MIP, maximal inspiratory pressure. 


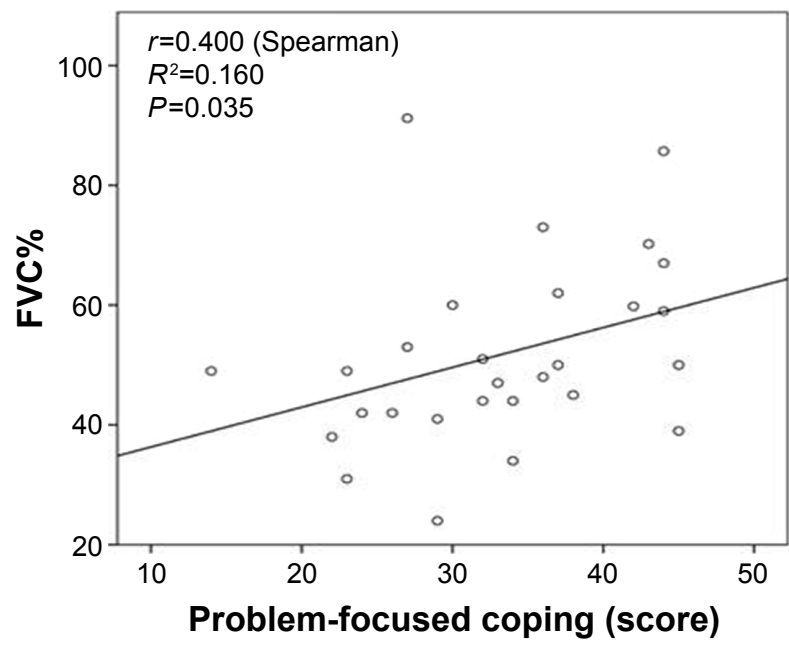

Figure I Correlation between problem-focused coping score and FVC\%. Abbreviation: FVC, forced vital capacity.

In patients suffering from lung disease, passive copings have been associated with a low quality of life, with a decrease in their professional performance, and with a worse mental state (as the presence of depression) although negative findings have also been reported. ${ }^{25-29}$

Moreover, a style of active coping (including problemfocused coping type), in patients with chronic somatic diseases (including patients who suffer from lung disease), has been associated with a better health-related quality of life and mental health symptoms. ${ }^{26,30-32}$ While problem-focused coping type is considered adaptive and is negatively associated with stress, depression, and anxiety, avoidant coping is considered maladaptive and is associated positively with these. ${ }^{33-36}$ With regard to the emotion-focused coping and social support-focused coping, the findings in the literature are contradictory as to their association with stress, anxiety, and depression symptoms. This happens mainly as a result

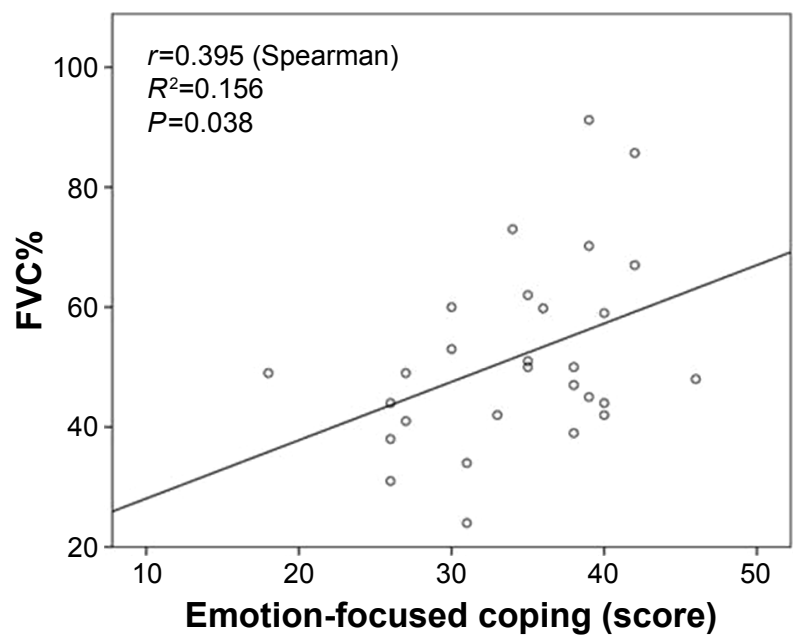

Figure 2 Relationship between emotion-focused coping score and FVC\%. Abbreviation: FVC, forced vital capacity.

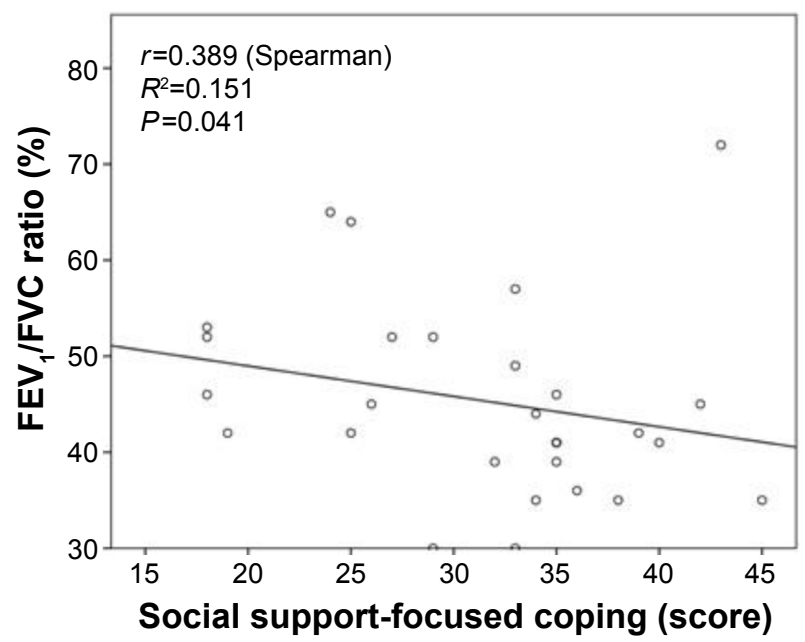

Figure 3 Correlation between social support-focused coping score and FEV /FVC ratio. Abbreviations: $\mathrm{FEV}_{1}$, forced expiratory volume in I second; FVC, forced vital capacity.

of the coping mechanisms that form these styles (levels) of coping as a consequence of the different definitions given in the literature. Therefore, emotion-focused coping contains positive interpretation, growth, abstinence, and acceptance. While positive interpretation, growth, and acceptance are considered active adaptive mechanisms, abstention has both an active and a passive one. ${ }^{36}$

At social support-focused coping, coping mechanisms such as utilization of emotional, instrumental, and social support and also manifestation of emotions are found. Seeking social and emotional support is considered active and adaptive coping mechanisms ${ }^{37}$ On the other hand, manifestation of emotions is considered in general a maladaptive coping even though some authors find an adaptive dimension of it. ${ }^{38,39}$

In this study, patients who had predominantly a problemfocused coping style had the most reduced depressive symptomatology and those who had an avoidant coping style had the most intense depressive symptomatology, in accordance with the literature. ${ }^{34,40}$ With respect to anxious depressive symptomatology, patients suffering from COPD who had a predominant emotion-focused coping had the lowest level of anxiety meanwhile those who had a social support-focused and an avoidant coping are associated positively with its intensity. If for emotion-focused coping and social supportfocused coping, the literature did not find any association between stress and anxious and depressive symptomatology, as it has been explained earlier, avoidant coping that was clearly mentioned has a positive association with the anxious symptomatology. ${ }^{34,41}$

Scharloo et $\mathrm{a}^{25}$ have also found a positive association between seeking social support and anxiety level in their study on 24 subjects suffering from COPD. Therefore, patients with the highest intensity of depression had a 
Table 4 Correlations between coping scales and respiratory parameters

\begin{tabular}{lllll}
\hline Parameters & $\begin{array}{l}\text { Problem-focused } \\
\text { coping }(\mathbf{n}=\mathbf{9})\end{array}$ & $\begin{array}{l}\text { Emotion-focused } \\
\text { coping }(\mathbf{n}=\mathbf{1 0})\end{array}$ & $\begin{array}{l}\text { Social support-focused } \\
\text { coping }(\mathbf{n}=\mathbf{6})\end{array}$ & $\begin{array}{l}\text { Avoidance-type } \\
\text { coping }(\mathbf{n}=\mathbf{3})\end{array}$ \\
\hline FVC (\%) & $0.400^{\mathrm{a}}$ & $0.395^{\mathrm{a}}$ & 0.344 & 0.294 \\
FEV $_{1}(\%)$ & 0.199 & 0.204 & -0.082 & -0.158 \\
FEV, IFVC (\%) & -0.024 & -0.172 & -0.389 & -0.217 \\
MIP (\%) & -0.030 & 0.159 & 0.086 & -0.017 \\
MEP (\%) & 0.204 & 0.102 & -0.002 & -0.087 \\
6MWT (\%) & 0.136 & 0.220 & -0.095 & -0.112 \\
Borg scale score & -0.216 & -0.223 & 0.015 & 0.273 \\
\hline
\end{tabular}

Notes: aCorrelations are significant at $\alpha<0.05$ level. Results are presented as Spearman's correlation coefficient.

Abbreviations: FVC, forced vital capacity; $\mathrm{FEV}_{1}$, forced expiratory volume in I second; 6MWT, 6-minute walking test; MEP, maximal expiratory pressure; MIP, maximal inspiratory pressure.

predominant avoidant coping style, and those with the highest intensity of anxiety had a predominant social support-focused coping. As to the association of the coping style with respiratory parameters and exercise tolerance, there are only few studies in the literature for COPD patients, and the existing relation between these has not been clarified until now. ${ }^{40,42,43}$

Buchi et $\mathrm{al}^{42}$ in their study on 32 subjects suffering from COPD have found a major impact of the coping strategies on the improvement of lung functionality evaluated through the modification of the $\mathrm{FEV}_{1}$ value; only one mechanism of coping, wishful thinking, is significantly associated with a greater improvement in $\mathrm{FEV}_{1}$.

The present study is the first study that uses the wellvalidated COPE on Romanian population for this purpose. Those who had a predominant social support-focused coping style had significantly lower values of $\mathrm{FVC}, \mathrm{FEV}_{1}$, and 6MWT but the highest values of MIP in comparison

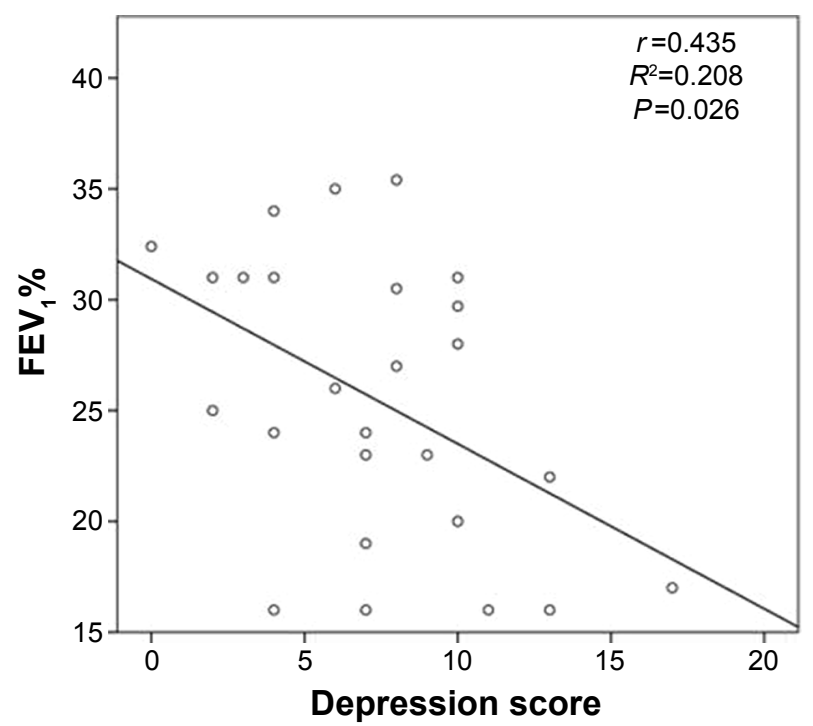

Figure 4 Correlation between depression score and $\mathrm{FEV}, \%$. Abbreviation: $\mathrm{FEV}_{1}$, forced expiratory volume in I second. with other subgroups. Considering the fact that social support-focused coping has been significantly associated in a positive way with the $\mathrm{FEV}_{1} / \mathrm{FVC}$ ratio and the intensity of the anxious symptomatology has been the highest in this subgroup, it can be concluded that this type of coping is maladaptive in COPD subjects, although there is a positive association with MIP values. This latter association could be caused by the inclusion of some coping mechanisms into this style of coping, mechanisms that are considered adaptive (social, instrumental, and emotional social support). There are studies that mention that the use of seeking social support-focused coping style is not associated with better outcomes in COPD patients. ${ }^{25,43}$

Subjects with a predominant problem-focused coping style had significantly higher FVC values and significantly smaller values on the BORG scale, and also the same values on the depressive intensity in comparison with the other subgroups. Considering the positive statistical association of the problem-focused coping style with FVC values, a conclusion about the adaptive style of this coping as to COPD can be drawn.

With reference to emotion-focused coping, the positive association of this with FVC values and the fact that the

Table 5 Correlations between depression, anxiety, and respiratory parameters

\begin{tabular}{lll}
\hline Parameters & Depression score & Anxiety score \\
\hline FVC (\%) & 0.084 & 0.114 \\
FEV $_{1}(\%)$ & $-0.435^{\mathrm{a}}$ & -0.132 \\
FEV $_{1} /$ FVC (\%) & -0.257 & -0.088 \\
MIP (\%) & 0.048 & 0.193 \\
MEP (\%) & -0.060 & 0.093 \\
6MWT (\%) & -0.108 & -0.093 \\
Borg scale score & 0.175 & 0.160 \\
\hline
\end{tabular}

Notes: ${ }^{2}$ Correlations are significant at $\alpha<0.05$ level. Results are presented as Spearman's correlation coefficient.

Abbreviations: FVC, forced vital capacity; $\mathrm{FEV}_{1}$, forced expiratory volume in I second; 6MWT, 6-minute walking test; MEP, maximal expiratory pressure; MIP, maximal inspiratory pressure. 
intensity of the anxious symptomatology has been the lowest in the sublot of coping predominant style, the emotionfocused one, it is also concluded that this is a coping adaptive style for subjects with COPD.

Thus, the beneficial/unbeneficial role of emotion-focused coping and social support-focused coping varies in the literature; in the present study on subjects with COPD, emotionfocused coping has a positive role in the evolution of COPD disease both on a physical and a psychic level and social support-focused coping has a negative impact. Research studies to prove whether the efficiency of different styles of coping varies according to the type of lung disease have not been carried out so far.

It is interesting that a significant statistical correlation between the coping style considered maladaptive, avoidantcoping, and respiratory parameters or exercise tolerance has not been found. But the subgroup of subjects who had avoidant coping as a main coping style was significantly different from the other subgroup in that they had the highest values at the 6MWT. This result differs from the one mentioned by Stoilkova et al, ${ }^{40}$ who has found that higher level of avoidance-type coping style was associated with a lower 6MWD.

The significant association between the different styles of coping is greater and more important, as it is not significantly intermediated by the intensity of depression and anxiety. So in this study the only significant association between respiratory parameters and psychiatric psychopathology was between the intensity of depression and $\mathrm{FEV}_{1}$ value. This is not enough to justify the significant association of coping styles with respiratory parameters, in this study, namely, the anxiety and depression represent confounding factors (the impact of the depression and anxiety on the functional status and on the patients with COPD physical health is well known). ${ }^{44-46}$ The exact interrelation between coping styles and these parameters warrants further investigation.

Until today, the relationship between coping styles and medical determinants in patients with COPD remains unknown. This could be explained by the fact that the use of an active coping style is related to higher self-esteem, life satisfaction, and compliance with medical advice, whereas avoidance-type coping style refers to poorer physical functioning in terms of depression, well-being, and functional disability. ${ }^{47}$ Thus, it could be a direct relationship and also an indirect one, mediated by psychiatric comorbidities. ${ }^{48}$ The studies that researched this aspect referred the aforementioned items as mechanisms, but all of them suggested the necessity of further studies in this area. ${ }^{49-52}$
The most important limitation of this study is the small sample size; however, a prior sample size analysis demonstrated that the study had an appropriate statistical power to support the conclusions drawn. Due to the small sample size, adjustment of the results with respect to other cofactors in a multivariate regression analysis was not possible. As a further direction, we aim at continuing the study in an increased cohort of patients, most probably in a multicenter setting. Another limitation of the study is the cross-sectional design, because it does not dynamically analyze the respiratory parameters, which may be an important predictor for the disease prognosis.

In case of a multidisciplinary approach, identifying the coping styles in patients with COPD represents an important aspect of the individualized treatment of the patient. Thus, for those with avoidant or social support-focused coping, psychological intervention such as cognitive behavior therapy is necessary to either support them or change them to more of a problem/emotional coping style. Cognitive behavior therapy is a form of psychotherapy useful for patients with COPD with maladaptive coping style as well as for those with psychiatric comorbidities such as depression and anxiety. ${ }^{53}$

The only relevant study that analyzes the prevalence of COPD in Romania has shown that in 10,000 people $23 \%$ has obstructive ventilator dysfunction. ${ }^{54}$ The present study is the first study that analyzes this type of association in the Romanian population with COPD. In our opinion, its importance is enhanced by the characteristics of this population, having significant evidence, which point out to a set of psychological particularities of the Romanian population when compared with other populations in which this relationship has been previously analyzed.

\section{Conclusion}

The study findings point out the following: a negative impact of avoidance and social support-focused coping types, on both depression and anxiety; two frequent comorbidities associated with COPD on the respiratory parameters in these patients, demonstrating the fact that interventions aiming at enhancing the problem- or emotion-focused coping may improve COPD prognosis.

Regarding biological parameters, significant correlations were found between problem-coping score, emotion-focused coping score, and $\mathrm{FVC} \%$ as well as between social supportfocused coping and $\mathrm{FEV}_{1} / \mathrm{FVC} \%$ ratio. Research studies on larger groups of patients are needed to clarify the correlation between each mechanism of coping with the biological parameters. 
This study demonstrates the paramount importance of the multidisciplinary approach in patients with COPD, emphasizing on the collaboration between the pulmonologist and the psychiatrist.

\section{Disclosure}

The authors report no conflicts of interest in this work.

\section{References}

1. Pommer AM, Pouwer F, Denollet J, Pop VJM. Managing co-morbid depression and anxiety in primary care patients with asthma and/or chronic obstructive pulmonary disease: study protocol for a randomized controlled trial. Trials. 2012;13:6-13.

2. Parekh PI, Blumenthal JA, Babyak MA, et al. Psychiatric disorder and quality of life in patients awaiting lung transplantation. Chest. 2003;124(5):1682-1688.

3. Kunik ME, Roundy K, Veazey C, et al. Surprisingly high prevalence of anxiety and depression in chronic breathing disorders. Chest. 2005; 127(4):1205-1211.

4. Hynninen KMJ, Breitve MH, Wiborg AB, Pallesen S, Nordhus IH. Psychological characteristics of patients with chronic obstructive pulmonary disease: a review. J Psychosom Res. 2005;59(6):429-443.

5. Lacasse Y, Rousseau L, Maltais F. Prevalence of depressive symptoms and depression in patients with severe oxygen-dependent chronic obstructive pulmonary disease. J Cardiopulm Rehabil. 2001;21(2): $80-86$.

6. Borak J, Sliwinski P, Piasecki Z, Zielinski J. Psychological status of COPD patients on long term oxygen therapy. Eur Respir J. 1991;4(1): $59-62$.

7. Vögele C, von Leupoldt A. Mental disorders in chronic obstructive pulmonary disease (COPD). Respir Med. 2008;102(5):764-773.

8. Van Manen JG, Bindels P, Dekker F, Jzermans CJI, van der Zee JS, Schade E. Risk of depression in patients with chronic obstructive pulmonary disease and its determinants. Thorax. 2002;57(5):412-416.

9. Doyle T, Palmer S, Johnson J, et al. Association of anxiety and depression with pulmonary-specific symptoms in chronic obstructive pulmonary disease. Int J Psychiatry Med. 2013;45(2):189-202.

10. Dalal AA, Shah M, Lunacsek O, et al. Clinical and economic burden of depression/anxiety in chronic obstructive pulmonary disease patients within a managed care population. COPD. 2011;8(4):293-299.

11. Atlantis E, Fahey P, Cochrane B, et al. Bidirectional associations between clinically relevant depression or anxiety and COPD: a systematic review and meta-analysis. Chest. 2013;144(3):766-777.

12. Sode BF, Dahl M, Nordestgaard BG. Myocardial infarction and other comorbidities with chronic obstructive pulmonary disease: a Danish Nationwide study of 7.4 million individuals. Eur Heart J. 2011;32(19): 2365-2375.

13. Yohannes AM, Alexoupolos GS. Depression and anxiety in patients with COPD. Eur Respir Rev. 2014;23(133):345-349.

14. Ferrer M, Alonso J, Morera J, et al. Chronic obstructive pulmonary disease stage and health-related quality of life. Ann Intern Med. 1997;127(12): 1072-1079.

15. Ketelaars CA, Schlosser MA, Mostert R, Huyer Abu-Saad H, Halfens RJ, Wouters EF. Determinants of health-related quality of life in patients with chronic obstructive pulmonary disease. Thorax. 1996;51(1): 39-43.

16. Wijnhoven HA, Kriegsman DM, Hesselink AE, de Haan M, Schellevis FG. The influence of co-morbidity on health-related quality of life in asthma and COPD patients. Respir Med. 2003;97(5):468-475.

17. Wijnhoven HA, Kriegsman DM, Hesselink AE, Pennix BW, de Haan M. Determinants of different dimensions of disease severity in asthma and COPD. Chest. 2001;119(4):1034-1042.
18. Habra ME, Linden W, Anderson JC, Weinberg J. Type D personality is related to cardiovascular and neuroendocrine reactivity to acute stress. J Psychosom Res. 2003;55(3):235-245.

19. Rabe KF, Hurd S, Anzueto A, et al. Global Initiative for Chronic Obstructive Lung Disease. Global strategy for the diagnosis, management, and prevention of chronic obstructive pulmonary disease: GOLD executive summary. Am J Respir Crit Care Med. 2007;176(6):532-555.

20. Mcelvaney G, Blackie S, Morrison NJ, Wilcox PG, Fairbarn MS, Pardy RI. Maximal static respiratory pressures in the normal elderly. Am Rev Respir Dis. 1989;139(1):277-281.

21. Carver CS, Scheier MF, Weintraub JK. Assessing coping strategies: a theoretically based approach. J Pers Soc Psychol. 1989;56(2):267-283.

22. Crasovan DI, Sava FA. Translation, adaptation and validation on Romanian population of COPE questionnaire for coping mechanisms analysis. Cogn Brain Behav. 2013;17(1):61-76.

23. ATS Committee on Proficiency Standards for Clinical Pulmonary Function Laboratories. ATS statement: guidelines for the six-minute walk test. Am J Respir Crit Care Med. 2002;166(1):111-117.

24. Tselebis A, Bratis D, Kosmas E, et al. Psychological symptom patterns and vital exhaustion in outpatients with chronic obstructive pulmonary disease. Ann Gen Psychiatry. 2011;10(1):32.

25. Scharloo M, Kaptein AA, Weinman JA, Willems LNA, Rooijmans HGM. Physical and psychological correlates of functioning in patients with chronic obstructive pulmonary disease. J Asthma. 2000;37(1): $17-29$.

26. Cohen F, Lazarus RS. Active coping processes, coping dispositions, and recovery from surgery. Psychosom Med. 1973;35(5):375-389.

27. Myaskovsky L, Dew MA, Switzer GE, et al. Avoidant coping with health problems is related to poorer quality of life among lung transplant candidates. Prog Transplant. 2003;13(3):183-192.

28. Burker EJ, Evon DM, Sedway JA, Egan T. Appraisal and coping as predictors of psychological distress and self-reported physical disability before lung transplantation. Prog Transplant. 2004;14(3):222-232.

29. De Vito DA, Dew MA, Stilley CS, et al. Psychosocial vulnerability, physical symptoms and physical impairment after lung and heart-lung transplantation. J Heart Lung Transplant. 2003;22(11):1268-1275.

30. Snow-Turek AL, Norris MP, Tan G. Active and passive coping strategies in chronic pain patients. Pain. 1996;64(3):455-462.

31. Taylor JL, Smith PJ, Babyak MA, et al. Coping and quality of life in patients awaiting lung transplantation. $J$ Psychosom Res. 2008;65(1): $71-79$.

32. Gibson K, Rueda S, Rourke SB, et al. Mastery and coping moderate the negative effect of acute and chronic stressors on mental health-related quality of life in HIV. AIDS Patient Care STDS. 2011;25(6):371-381.

33. Wijndaele K, Matton L, Duvigneaud N, et al. Association between leisure time physical activity and stress, social support and coping: a clusteranalytical approach. Psychol Sport Exerc. 2007;8(4):425-440.

34. Holahan CJ, Holahan CK, Moos RH, Brennan PL, Schutte KK. Stress generation, avoidance coping, and depressive symptoms: a 10-year model. J Consult Clin Psychol. 2005;73(4):658-666.

35. Sherbourne C, Hays RD, Wells KB. Personal and psychosocial risk factors for physical and mental health outcomes and course of depression among depressed patients. J Consult Clin Psychol. 1995;63(3): $345-355$.

36. Knibb RC, Horton SL. Can illness perceptions and coping predict psychological distress amongst allergy sufferers? Br J Health Psychol. 2008;13(1):103-119.

37. Hundt NE, Bensadon BA, Stanley MA, et al. Coping mediates the relationship between disease severity and illness intrusiveness among chronically ill patients. J Health Psychol. Epub 2013 Dec 1.

38. Bouteyre E, Maurel M, Bernaud JL. Daily hassles and depressive symptoms among first year psychology students in France: the role of coping and social support. Stress Health. 2007;23(2):93-99.

39. Ninot G, Fortes M, Poulain M, et al. Gender difference in coping strategies among patients enrolled in an inpatient rehabilitation program. Heart Lung. 2006;35(2):130-136. 
40. Stoilkova A, Wouters EFM, Spruit MA, Franssen FME, Janssen DJA. The relationship between coping styles and clinical outcomes in patients with COPD entering pulmonary rehabilitation. COPD. 2013; 10(3):316-323.

41. Crockett LJ, Iturbide MI, Torres Stone RA, McGinley M, Raffaelli M, Carlo G. Acculturative stress, social support, and coping: Relations to psychological adjustment among Mexican American college students. Cultur Divers Ethnic Minor Psychol. 2007;13(4):347-355.

42. Buchi S, Villiger B, Sensky T, et al. Psychosocial predictors of longterm success of in-patient pulmonary rehabilitation of patients with COPD. Eur Respir J. 1997;10(6):1272-1277.

43. Stoilkova A, Janssen DJA, Franssen FME, Spruit MA, Wouters EFM. Coping styles in patients with COPD before and after pulmonary rehabilitation. Respir Med. 2013;107(6):825-833.

44. Yohannes AM, Baldwin RC, Connolly MJ. Depression and anxiety in elderly outpatients with chronic obstructive pulmonary disease: prevalence, and validation of the BASDEC screening questionnaire. Int J Geriatr Psychiatry. 2000;15(12):1090-1096.

45. Felker B, Katon W, Hedrick SC, et al. The association between depressive symptoms and health status in patients with chronic pulmonary disease. Gen Hosp Psychiatry. 2001;23(2):56-61.

46. Cleland JA, Lee AJ, Hall S. Associations of depression and anxiety with gender, age, health-related quality of life and symptoms in primary care COPD patients. Fam Pract. 2007;24(3):217-223.
47. Maes S, Leventhal H, de Ridder DTD. Coping with chronic illness In: Zeidner M, Endler NS, editors. Handbook of Coping. New York: Wiley \& Sons; 1996:221-251.

48. Giltay EJ, Zitman FG, Kromhout D. Dispositional optimism and the risk of depressive symptoms during 15 years of follow-up: The Zutphen Elderly Study. J Affect Disorder. 2006;91(1):45-52.

49. Hand $\mathrm{CH}$, Bradley $\mathrm{C}$. Health beliefs of adults with asthma: toward an understanding of the differences between symptomatic and preventive use of inhaler treatment. J Asthma. 1996;33(5):331-338.

50. Klag S, Bradley G. The role of hardiness in stress and illness: an exploration of the effect of negative affectivity and gender. Br J Health Psychol. 2004;9(2):137-161.

51. Flensborg-Madsen T, Ventegodt S, Merrick J. Sense of coherence and physical health. A review of previous findings. ScientificWorldJournal. 2005;5:665-673.

52. Eschleman KJ, Bowling NA, Alarcon GM. A meta-analytic examination of hardiness. Int JStress Manag. 2010;17(4):277-307.

53. Popa-Velea O, Purcarea VL. Psychological intervention - a critical element of rehabilitation in chronic pulmonary diseases. JMed Life. 2014; 2(7):274-281.

54. Mihaltan F, Furtunescu F, Nemes R, et al. Prevalenta BPOC in Romania 2011-2012 - Prima ancheta national ace a inclus si explorarea functional spirometrica, Studiu realizat de TOTEM Research pentru Centrul pentru Politici si Servicii de Sanatate.
International Journal of COPD

\section{Publish your work in this journal}

The International Journal of COPD is an international, peer-reviewed journal of therapeutics and pharmacology focusing on concise rapid reporting of clinical studies and reviews in COPD. Special focus is given to the pathophysiological processes underlying the disease, intervention programs, patient focused education, and self management protocols.

\section{Dovepress}

This journal is indexed on PubMed Central, MedLine and CAS. The manuscript management system is completely online and includes a very quick and fair peer-review system, which is all easy to use. Visit http://www.dovepress.com/testimonials.php to read real quotes from published authors. 